\title{
Increased Risk of Meconium-Related lleus in Extremely Premature Infants Exposed to Antenatal Magnesium Sulfate
}

\author{
Se In Sung ${ }^{a}$ So Yoon Ahn ${ }^{a}$ Suk-Joo Choi ${ }^{b}$ Soo-young Oh ${ }^{b}$ \\ Cheong-Rae Roh ${ }^{b}$ Misun Yang ${ }^{\text {a }}$ Yun Sil Chang ${ }^{a}$ Won Soon Park \\ aDepartment of Pediatrics, Samsung Medical Center, Sungkyunkwan University School of Medicine, Seoul, South \\ Korea; ${ }^{b}$ Department of Obstetrics and Gynecology, Samsung Medical Center, Sungkyunkwan University School of \\ Medicine, Seoul, South Korea
}

\section{Keywords}

Meconium · Meconium-related ileus · Antenatal magnesium sulfate $\cdot$ Neuroprotection $\cdot$ Extremely premature infants

\begin{abstract}
Introduction: We experienced an increased incidence of meconium-related ileus (MRI) in extremely premature infants (EPIs) while adopting the antenatal magnesium sulfate $\left(\mathrm{MgSO}_{4}\right)$ protocol for fetal neuroprotection in our neonatal intensive care unit. This study aimed to test whether antenatal $\mathrm{MgSO}_{4}$ use was associated with increased risk of MRI in EPIs. Methods: The incidences of complicated MRI requiring aggressive enema or surgical intervention and other intestinal complications were compared among period 1 (January 2012-December 2013, $n=79$ ), before adoption of the antenatal $\mathrm{MgSO}_{4}$ protocol for fetal neuroprotection; period 2 (January 2014-March 2016, $n=72$ ), when the protocol was adopted; and period 3 (April 2016-September 2018, $n=75$ ), when the protocol was temporarily withdrawn due to concern regarding intestinal complications in EPIs. Results: Despite similar baseline clinical characteristics among infants across the study periods, the MRI and MRI with surgical treat-
\end{abstract}

\section{karger@karger.com} www.karger.com/neo

Karger"
(C) 2022 The Author(s)

Published by S. Karger AG, Basel

This is an Open Access article licensed under the Creative Commons Attribution-NonCommercial-4.0 International License (CC BY-NC) (http://www.karger.com/Services/OpenAccessLicense), applicable to the online version of the article only. Usage and distribution for commercial purposes requires written permission. ment incidences were higher in period 2 than those in periods 1 and 3 (13\% vs. $8 \%$ and $6 \%, p=0.391$, and $11 \%$ vs. $0 \%$ and $1 \%, p=0.001$, respectively). In multivariable analysis, exposure to antenatal $\mathrm{MgSO}_{4}$ independently increased the risk of MRI (adjusted odds ratio, 3.8; 95\% confidence interval, 1.4, 10.6). Conclusion: Antenatal $\mathrm{MgSO}_{4}$ may increase the risk of $\mathrm{MRI}$, frequently requiring surgical intervention, in EPIs with a gestational age of 25 weeks or less.

(c) 2022 The Author(s).

Published by S. Karger AG, Basel

\section{Introduction}

Although $\mathrm{MgSO}_{4}$ is no longer recommended for tocolysis according to a recent systematic review, it has been widely used as a tocolytic agent for the treatment of eclampsia and preeclampsia [1-3]. Since the fetal neuroprotective effect of antenatal $\mathrm{MgSO}_{4}$ was suggested in 1995 [4], 4 large randomized clinical trials (RCTs) and subsequent meta-analysis showed that antenatal $\mathrm{MgSO}_{4}$ could reduce cerebral palsy and gross motor dysfunction in survivors [5-12]. In 2010, the American College of Obstetricians and Gynecologists (ACOG) recommended the use of antenatal $\mathrm{MgSO}_{4}$ in women at risk of preterm birth
Correspondence to:

Yun Sil Chang, yschang@skku.edu 
before 32 weeks of gestation, although the meta-analyses did not include a sufficient number of infants with a gestational age (GA) of 25 weeks or less [9, 10, 13].

Accordingly, the protocol for the antenatal use of $\mathrm{MgSO} 4$ for fetal neuroprotection was adopted in our routine practice in January 2014. However, we thereafter observed an increased incidence of neonatal meconium problems including delayed meconium passage, feeding intolerance, abdominal distention, severe ileus on plain abdominal radiographs, and need for an aggressive enema procedure with gastrografin or surgical intervention, suggesting the diagnosis of meconium-related ileus (MRI). MRI developed exclusively in extremely preterm infants (EPIs) born at a GA of 25 weeks or less. Because of this observation and a literature review showing an association between $\mathrm{MgSO}_{4}$ and neonatal intestinal complications including necrotizing enterocolitis (NEC) and spontaneous intestinal perforation (SIP) $[14,15]$, we withdrew the protocol for routine $\mathrm{MgSO}_{4}$ use for fetal neuroprotection in March 2016. Therefore, the purpose of the present study was to thoroughly investigate whether antenatal $\mathrm{MgSO}_{4}$ use for fetal neuroprotection was associated with increased risk of MRI in EPIs by comparing the incidence of MRI among the periods before, during, and after the adoption of the routine $\mathrm{MgSO}_{4}$ protocol.

\section{Methods}

The medical records of 231 EPIs born from 22 weeks, 0 days, to 25 weeks, 6 days, of gestation and admitted to the Samsung Medical Center neonatal intensive care unit (NICU) between July 2012 and December 2018 were reviewed. Infants who died within the first $48 \mathrm{~h}(n=2)$, had congenital intestinal anomalies $(n=1$, esophageal atresia), or were born at another hospital $(n=2)$ were excluded; a total of 226 infants were finally included and analyzed in this study. In period 1 (January 2012-December 2013, $n=79$ ), antenatal $\mathrm{MgSO}_{4}$ was used to treat eclampsia/preeclampsia or for tocolytic purposes. In period 2 (January 2014-March 2016, $n=72$ ), antenatal $\mathrm{MgSO}_{4}$ was routinely used for fetal neuroprotection, apart from the conventional purposes of preterm delivery. However, the routine use protocol of antenatal $\mathrm{MgSO}_{4}$ for fetal neuroprotection was withdrawn because of concerns about intestinal complications including MRI in EPIs (period 3, April 2016-September 2018, $n=75$ ). Antenatal $\mathrm{MgSO}_{4}$ treatment for fetal neuroprotection was administered with an intravenous loading dose of $4 \mathrm{~g}$ over 15-20 min, followed by a maintenance infusion of $1 \mathrm{~g}$ per hour for $24 \mathrm{~h}$ for women having imminent preterm. For the treatment of severe preeclampsia and eclampsia, $\mathrm{MgSO}_{4}$ was administered at the same loading dose, followed by a maintenance infusion of $1 \mathrm{~g}$ per hour and discontinued at $24 \mathrm{~h}$ after delivery. As we did not use antenatal $\mathrm{MgSO}_{4}$ as a tocolytic, the data regarding $\mathrm{MgSO}_{4}$ use for tocolysis were based on medical charts from another hospital before the women were transferred.

Meconium Ileus and Antenatal $\mathrm{MgSO}_{4}$

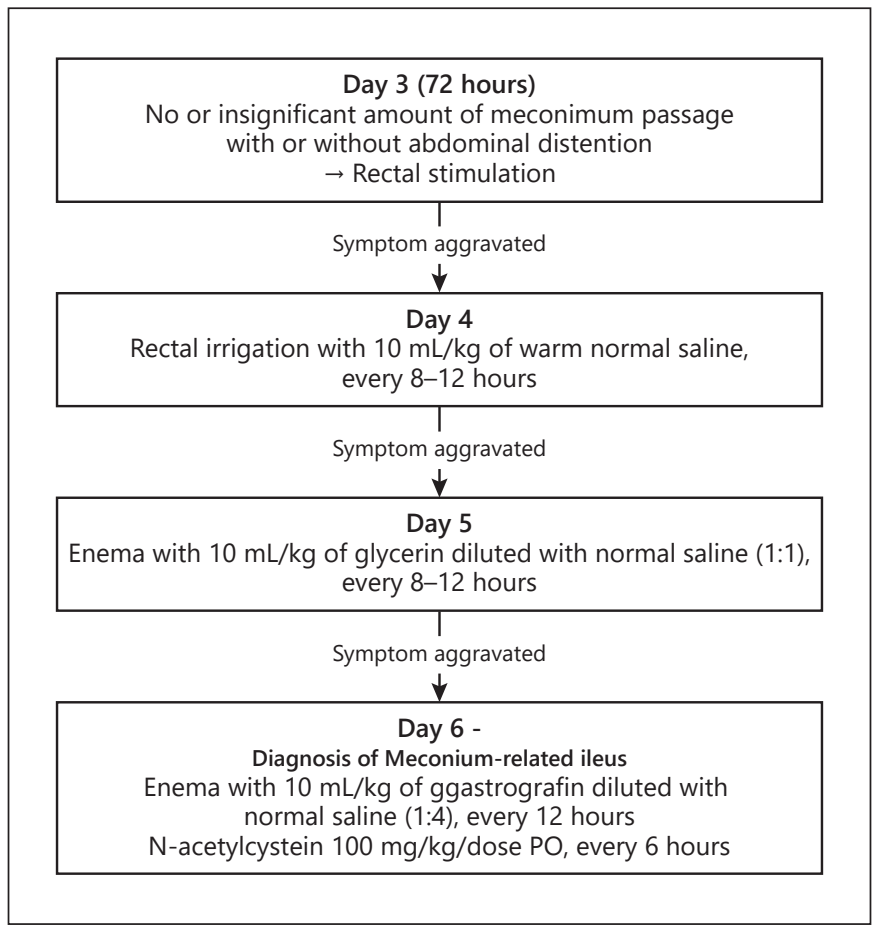

Fig. 1. Enema protocol for delayed meconium passage in extremely premature infants.

MRI is defined as an intestinal obstruction due to meconium without cystic fibrosis [16-18]. In the present study, MRI was suspected in infants showing severe abdominal distention, feeding intolerance, marked ileus on abdominal radiography, and no meconium passage for the first 5 days after birth in the absence of other intestinal diseases including NEC, SIP, intestinal atresia, or anorectal malformation. Together with the clinical symptoms described above, we defined MRI as requiring a gastrografin enema with or without the assistance of abdominal ultrasonography on day 6 of life or after $[19,20]$. In the absence of any symptoms/signs, delayed meconium passage was not diagnosed by MRI and was not treated. In contrast to MRI, NEC was staged in accordance with the modified Bell's criteria. NEC $(\geq 2 b)$ was diagnosed when there was definite radiographic evidence of pneumatosis intestinalis and ascites, along with the characteristic systemic and abdominal signs. In the surgical NEC cases, the diagnosis was confirmed on the basis of intraoperative findings of necrotic bowel and histologic findings, including ischemic necrosis.

Figure 1 illustrates the MRI management protocol in our unit. In the case of meconium obstruction with intestinal perforation, emergency surgical intervention of manual meconium evacuation and stoma formation was performed. Even without intestinal perforation, surgery was performed in the case of severe and progressive ileus accompanied by metabolic acidosis $(\mathrm{pH}<7.1)$ and/or respiratory compromise (increase in ventilator settings) directly due to severe abdominal distention. Minimal enteral feeding (20 $\mathrm{mL} / \mathrm{kg} /$ day) was usually started within the first few hours after birth and maintained for the first week of life. The infants were fed with formula for the first 2-3 days of life and their mother's breast 
Table 1. Baseline and $\mathrm{MgSO}_{4}$-related clinical characteristics of the study population

\begin{tabular}{|c|c|c|c|c|}
\hline & Period $1(n=79)$ & Period $2(n=72)$ & Period $3(n=75)$ & $p$ value \\
\hline \multicolumn{5}{|l|}{ Baseline characteristics } \\
\hline Gestational age, weeks (min, max) & $24.0 \pm 0.9\left(22^{+1}, 25^{+6}\right)$ & $24.2 \pm 0.1\left(22^{+5}, 25^{+6}\right)$ & $23.9 \pm 0.9\left(22^{+1}, 25^{+6}\right)$ & 0.201 \\
\hline Male, $n(\%)$ & $45(57)$ & $39(54)$ & $39(52)$ & 0825 \\
\hline Small for gestational age, $n(\%)$ & $13(16)$ & $11(15)$ & $13(17)$ & 0.945 \\
\hline Apgar score at $1 \mathrm{~min}$ & $4.3 \pm 1.6$ & $4.4 \pm 1.4$ & $4.3 \pm 1.7$ & 0.957 \\
\hline Antenatal steroid use, $n(\%)$ & $76(94)$ & $66(92)$ & $73(97)$ & 0.325 \\
\hline Preterm premature rupture of membranes, $n(\%)$ & $30(38)$ & $22(31)$ & $37(49)$ & 0.063 \\
\hline Histologic chorioamnionitis, $n(\%)$ & $50(63)$ & $40(56)$ & $57(87)$ & 0.031 \\
\hline Preeclampsia, $n(\%)$ & $5(6)$ & $6(8)$ & $4(5)$ & 0.759 \\
\hline Gestational diabetes, $n(\%)$ & $2(3)$ & $1(1)$ & $1(1)$ & 0.816 \\
\hline \multicolumn{5}{|l|}{ Antenatal $\mathrm{MgSO}_{4}$ use, $n(\%)$} \\
\hline For tocolysis & $13(16)$ & $10(14)$ & $12(16)$ & $<0.001$ \\
\hline \multicolumn{5}{|l|}{ Serum $\mathrm{MgSO}_{4}$ level of EPIs } \\
\hline Initial level (<1 h), mg/dL & $2.6 \pm 1.3$ & $2.8 \pm 0.9$ & $2.3 \pm 0.6$ & 0.021 \\
\hline Peak level within the first week, $\mathrm{mg} / \mathrm{dL}$ & $2.8 \pm 1.0$ & $3.0 \pm 0.7$ & $2.7 \pm 0.5$ & $<0.001$ \\
\hline Initial ionized calcium level, mmol/L & $1.26 \pm 0.17$ & $1.28 \pm 0.14$ & $1.25 \pm 0.15$ & 0.408 \\
\hline Total intake on day $1, \mathrm{~mL} / \mathrm{kg} /$ day & $70 \pm 7$ & $73 \pm 6$ & $71 \pm 10$ & 0.888 \\
\hline Total intake on day $7, \mathrm{~mL} / \mathrm{kg} /$ day & $110 \pm 12$ & $109 \pm 18$ & $113 \pm 13$ & 0.932 \\
\hline \multicolumn{5}{|l|}{ Type of milk during the first month or until alive, $n(\%)$} \\
\hline Exclusive breastfeeding & $34(43)$ & $37(51)$ & $40(53)$ & \multirow{2}{*}{0.231} \\
\hline Partial breastfeeding & $31(39)$ & $23(32)$ & $31(41)$ & \\
\hline
\end{tabular}

milk thereafter. We subsequently increased the feeding amount at the end of the first week in increments of $10-20 \mathrm{~mL} / \mathrm{kg} /$ day to reach full feeding $(120-150 \mathrm{~mL} / \mathrm{kg} /$ day) if tolerated. The feeding protocol was applied consistently throughout the study period.

We collected data on baseline clinical characteristics including GA, birth weight, sex, Apgar scores at 1 and 5 min, cesarean section, histologic chorioamnionitis, and other perinatal data. Data on gestational diabetes and small for gestational age were also collected because they are known to be associated with delayed meconium passage [21, 22]. Histologic chorioamnionitis was defined according to the criteria of Redline et al. [23]. Data on antenatal $\mathrm{MgSO}_{4}$ use and the initial and peak serum magnesium levels in the neonatal patients were also collected. We also collected data on the serum ionized calcium level, small for gestational age status, and gestational age because these could affect the serum magnesium level in neonates. The major neonatal outcome data, including mortality, intraventricular hemorrhage (grades III and IV), retinopathy of prematurity ( $\geq$ stage 3 ), moderate to severe bronchopulmonary dysplasia, and blood culture-proven sepsis during hos- pitalization, were collected. The neurodevelopmental outcomes at the corrected age of 18-24 months included the incidence of cerebral palsy, defined as a Palisano gross motor function score of $\geq 2$, bilateral hearing loss, bilateral visual loss, cognitive impairment, psychomotor impairment, and $z$-score of weight, height, and head circumference. Cognitive impairment was defined as a mental developmental index of $<70$ on the Bayley Scales of Infant Development (BSID) II or a cognitive score of $<70$ or a language score of $<70$ on the BSID-III. Psychomotor impairment was defined as a psychomotor developmental index of $<70$ on the BSID-II or a motor score of $<70$ on the BSID-III. The intestinal complications included MRI, MRI requiring surgery, NEC, and SIP. NEC was staged according to modified Bell's criteria; SIP was defined based on surgical and/or histologic findings of the absence of ischemic bowel change with or without focal hemorrhagic necrosis [24]. We also collected surgical outcome data for MRI, including operative findings, procedures, postnatal age at operation, and take-down operations. 
Table 2. Neonatal outcomes including intestinal complications in extremely premature infants

$\begin{array}{llll}\begin{array}{l}\text { Period 1 } \\ (n=79)\end{array} & \begin{array}{l}\text { Period 2 } \\ (n=72)\end{array} & \begin{array}{l}\text { Period 3 } \\ (n=75)\end{array} & p \text { value }\end{array}$

\begin{tabular}{|c|c|c|c|c|}
\hline \multicolumn{5}{|l|}{ Intestinal complication, $n$ (\%) } \\
\hline Meconium-related ileus requiring surgery & $0(0)$ & $8(11)$ & $1(1)$ & 0.001 \\
\hline Spontaneous intestinal perforation & $1(1)$ & $2(3)$ & $4(5)$ & 0.340 \\
\hline Necrotizing enterocolitis, stage $\geq 2 b$ & $16(20)$ & $22(31)$ & $19(25)$ & 0.346 \\
\hline Necrotizing enterocolitis perforation & $9(11)$ & $8(11)$ & $9(12)$ & 0.768 \\
\hline $\begin{array}{l}\text { Intestinal surgery for spontaneous intestinal perforatio } \\
\text { enterocolitis perforation }\end{array}$ & $10(13)$ & $10(14)$ & $13(17)$ & 0.823 \\
\hline \multicolumn{5}{|l|}{ Other neonatal outcomes, $n(\%)$} \\
\hline In-hospital mortality & $16(20)$ & $19(26)$ & $29(39)$ & 0.037 \\
\hline Intraventricular hemorrhage grade III-IV & $14(18)$ & $14(20)$ & $7(10)$ & 0.183 \\
\hline Retinopathy of prematurity stage $\geq 3$ & $25(32)$ & $20(28)$ & $11(29)$ & 0.890 \\
\hline Bronchopulmonary dysplasia, moderate to severe & $32(41)$ & $33(46)$ & $44(59)$ & 0.070 \\
\hline Acute kidney injury & $6(8)$ & $5(7)$ & $2(3)$ & 0.368 \\
\hline Blood culture-proven sepsis & $35(44)$ & $22(31)$ & $27(36)$ & 0.211 \\
\hline \multicolumn{5}{|c|}{ Neurodevelopmental outcomes at the corrected age of 18-24 months } \\
\hline Mortality after hospital discharge, $n(\%)$ & $0(0)$ & $0(0)$ & $0(0)$ & \\
\hline Cerebral palsy, $n(\%)$ & $6 / 60(10)$ & $4 / 52(8)$ & $6 / 44(14)$ & 0.631 \\
\hline Hearing loss, $n(\%)$ & $1 / 60(2)$ & $2 / 52(4)$ & $2 / 44(5)$ & 0.677 \\
\hline Blindness, $n(\%)$ & $3 / 60(5)$ & $0 / 52(0)$ & $0 / 44(0)$ & 0.087 \\
\hline Cognitive impairment, $n$ (\%) & $14 / 40(35)$ & $23 / 48(48)$ & $14 / 40(35)$ & 0.352 \\
\hline Psychomotor impairment, $n(\%)$ & $14 / 40(35)$ & $12 / 48(25)$ & $9 / 40(23)$ & 0.475 \\
\hline Weight (z-score) & $-1.16 \pm 1.32$ & $-1.07 \pm 0.99$ & $-0.80 \pm 0.99$ & 0.323 \\
\hline Height (z-score) & $-1.18 \pm 1.32$ & $-1.11 \pm 1.21$ & $-1.04 \pm 1.23$ & 0.853 \\
\hline Head circumference (z-score) & $-0.95 \pm 1.22$ & $-0.79 \pm 0.96$ & $-1.23 \pm 1.46$ & 0.237 \\
\hline
\end{tabular}

Baseline characteristics and outcomes were compared among periods 1,2 , and 3 using $\chi^{2}$ or Fisher's exact tests for categorical variables, analysis of variance or Student's $t$ test for parametric continuous variables, and Kruskal-Wallis test or Wilcoxon ranksum tests for nonparametric continuous variables. Binary logistic regression was used to calculate the adjusted odds ratios (ORs) of the exposure versus nonexposure to antenatal $\mathrm{MgSO}_{4}$ for intestinal complications. The variables adjusted for in the multivariable analyses included the gestational age, antenatal steroid use, and histologic chorioamnionitis. $p$ values of $<0.05$ were considered statistically significant. Statistical analysis was performed using SAS version 9.4 (SAS Institute Inc., Cary, NC, USA) and STATA 14.0 (StataCorp, College Station, TX, USA). The Institutional Review Board of the Samsung Medical Center approved the study and waived the requirement for informed consent for the retrospective chart review (IRB No. SMC 2016-09-113).

\section{Results}

Ninety-one (40\%) infants received antenatal $\mathrm{MgSO}_{4}$ during the study periods (Table 1 ). The rate of antenatal $\mathrm{MgSO}_{4}$ use was the highest in period 2 (78\%) compared to the rates in periods 1 (24\%) and 3 (21\%). Regarding baseline characteristics, infants in period 3 showed a significantly lower rate of cesarean section and a higher rate of histologic chorioamnionitis. Otherwise, there were no differences among the periods. The serum $\mathrm{MgSO}_{4}$ level tested within the first hour of life was the highest in period $2(2.8 \pm 0.9 \mathrm{mg} / \mathrm{dL})$ compared to the levels in periods $1(2.6 \pm 1.3)$ and $3(2.3 \pm 0.6 \mathrm{mg} / \mathrm{dL})$. Similarly, the peak serum $\mathrm{MgSO}_{4}$ level within the first week was the highest in period 2 compared to those in periods 1 and 3 . These initial and peak serum $\mathrm{MgSO}_{4}$ levels were within the reference range, according to a recently published metaanalysis showing the changes in the serum magnesium level in preterm infants [25]. In addition, there was no difference in the breastfeeding rate between the periods.

Although the incidence of MRI was the highest in period 2 compared to those in periods 1 and 3 , the difference did not reach statistical significance (Table 2). However, the number of infants who underwent surgery due to MRI was significantly higher in period $2(8 / 72,11 \%)$, whereas none and 1 infant underwent surgery due to MRI 
Table 3. Surgical outcomes of MRI

\begin{tabular}{|c|c|c|c|c|c|c|c|c|}
\hline $\begin{array}{l}\text { Case (GA, weeks; } \\
\text { birth weight, g) }\end{array}$ & Period & $\begin{array}{l}\text { Antenatal } \\
\mathrm{MgSO}_{4} \\
\text { (purpose) }\end{array}$ & $\begin{array}{l}\text { Operative finding } \\
\text { and procedure }\end{array}$ & $\begin{array}{l}\text { Ostomy } \\
\text { formation }\end{array}$ & $\begin{array}{l}\text { Date of } \\
\text { operation, } \\
\text { postnatal day }\end{array}$ & $\begin{array}{l}\text { Take-down operation } \\
\text { (postnatal day) }\end{array}$ & $\begin{array}{l}\text { Mortality } \\
\text { during } \\
\text { hospitalization }\end{array}$ & Cause of death \\
\hline$\# 3\left(25^{+2} ; 750\right)$ & 2 & $+(N P)$ & $\begin{array}{l}\text { Ileal meconium } \\
\text { obstruction and } \\
\text { perforation }\end{array}$ & lleostomy & 26 & $+(156)$ & & \\
\hline$\# 5\left(23^{+4} ; 660\right)$ & 2 & $+(\mathrm{NP})$ & $\begin{array}{l}\text { Ileal meconium } \\
\text { obstruction and } \\
\text { perforation }\end{array}$ & Ileostomy & 11 & $+(108)$ & & \\
\hline$\# 6\left(22^{+5} ; 500\right)$ & 2 & $+(\mathrm{NP})$ & $\begin{array}{l}\text { Ileal meconium } \\
\text { obstruction and } \\
\text { perforation }\end{array}$ & Ileostomy & 12 & $\begin{array}{l}\text { Expired before take- } \\
\text { down operation }\end{array}$ & + & $\begin{array}{l}\text { Peritonitis after } \\
\text { MRI surgery }\end{array}$ \\
\hline$\# 7\left(22^{+5} ; 450\right)$ & 2 & - & $\begin{array}{l}\text { Jejunal meconium } \\
\text { obstruction }\end{array}$ & Jejunostomy & 30 & $\begin{array}{l}\text { Expired before take- } \\
\text { down operation }\end{array}$ & + & \\
\hline$\# 8\left(24^{+1} ; 690\right)$ & 2 & $+(\mathrm{NP})$ & $\begin{array}{l}\text { Ileal meconium } \\
\text { obstruction }\end{array}$ & lleostomy & 38 & $+(120)$ & & $\begin{array}{l}\text { Acute kidney } \\
\text { injury }\end{array}$ \\
\hline
\end{tabular}

GA, gestational age; PE, preeclampsia treatment; NP, neuroprotection; MRI, meconium-related ileus; TO, tocolytic purpose.

during periods 1 and 3 , respectively. There were no cases of cystic fibrosis during the study period. There were no differences in the incidence of NEC, SIP, and intestinal surgery among the study periods. Among other neonatal outcome variables, in-hospital mortality was significantly higher in period 3 than those in periods 1 and 2; otherwise, there were no differences. Further analysis adjusting the rate of cesarean section and chorioamnionitis showed no difference in the in-hospital mortality among the 3 periods $(p=0.337)$. There were also no differences in the neurodevelopmental outcomes at the corrected age of 18-24 months. The surgical outcomes of the infants who underwent surgical procedures due to MRI are shown in Table 3. Among the 9 infants who underwent surgery for
MRI, 7 had received antenatal $\mathrm{MgSO}_{4}$, and 5 infants died during NICU hospitalization. One infant died on day 42 due to peritonitis following MRI surgery.

In the multivariable analysis, the adjusted ORs of $\mathrm{MgSO}_{4}$ exposed versus unexposed for MRI and MRI requiring surgery, respectively, were 3.8 (95\% confidence interval [CI]: 1.4, 10.6) and 14.1 (95\% CI: 2.1, 92.2), a statistically significant difference (Table 4 ). The adjusted OR of $\mathrm{MgSO}_{4}$ exposure for fetal neuroprotection versus unexposed for MRI was 3.6 (95\% CI: 1.1, 13.2). In contrast, no differences in adjusted ORs were observed for NEC, SIP, or intestinal surgery for any reason between $\mathrm{MgSO}_{4-}$ exposed and - unexposed infants. The risk of MRI requiring surgical treatment was increased independently in in- 
Table 4. The risks of intestinal complications in extremely premature infants with and without exposure to antenatal $\mathrm{MgSO}_{4}$

\begin{tabular}{|c|c|c|c|c|c|c|}
\hline & $\begin{array}{l}\mathrm{MgSO}_{4} \text { exposed, } \\
n(\%)(N=91)\end{array}$ & $\begin{array}{l}\mathrm{MgSO}_{4} \text { exposed for } \\
\text { fetal neuroprotection, } \\
n(\%)(N=41)\end{array}$ & $\begin{array}{l}\mathrm{MgSO}_{4} \text { unexposed } \\
n(\%)(N=135)\end{array}$ & $p$ value* & $p$ value $^{\dagger}$ & $\begin{array}{l}\text { Adjusted OR } \\
(95 \% \mathrm{Cl})\end{array}$ \\
\hline Meconium-related ileus & $13(14)$ & $5(12)$ & $7(5)$ & 0.018 & 0.119 & $3.8(1.4,10.6)$ \\
\hline Meconium-related ileus requiring surgery & $7(8)$ & $4(10)$ & $2(2)$ & 0.019 & 0.011 & $14.1(2.1,92.2)$ \\
\hline Spontaneous intestinal perforation & $3(3)$ & $1(2)$ & $4(3)$ & 0.887 & 0.860 & $1.1(0.2,5.4)$ \\
\hline Necrotizing enterocolitis stage $\geq 2 b$ & $21(23)$ & $11(27)$ & $36(27)$ & 0.542 & 0.984 & $0.9(0.5,1.7)$ \\
\hline Necrotizing enterocolitis perforation & $6(7)$ & $3(7)$ & $20(14)$ & 0.057 & 0.212 & $0.5(0.2,1.2)$ \\
\hline Intestinal surgery for any reason & $13(14)$ & $7(17)$ & $26(19)$ & 0.332 & 0.753 & $0.9(0.4,1.9)$ \\
\hline
\end{tabular}

$\mathrm{MgSO}_{4}$, magnesium sulfate; $\mathrm{OR}$, odds ratio; $\mathrm{Cl}$, confidence interval. ${ }^{*} \mathrm{MgSO}_{4}$ exposed versus $\mathrm{MgSO}_{4}$ unexposed. ${ }^{\dagger} \mathrm{MgSO}_{4}$ exposed for fetal neuroprotection versus $\mathrm{MgSO}_{4}$ unexposed. ${ }^{a}$ Odds ratios of $\mathrm{MgSO}_{4}$ exposed versus $\mathrm{MgSO}_{4}$ unexposed, adjusted for gestational age, antenatal steroid use, and histologic chorioamnionitis.

fants with a lower GA (adjusted OR: 0.3, 95\% CI: 0.1, 0.67 per week increase of GA) and with exposure to antenatal $\mathrm{MgSO}_{4}$ (adjusted OR: 14.1, 95\% CI: 2.1, 92.2).

\section{Discussion}

The results of the present study demonstrated the association between antenatal $\mathrm{MgSO}_{4}$ use and neonatal MRI in EPIs. Infants who were exposed to antenatal $\mathrm{MgSO}_{4}$ for any reason or for the sake of fetal neuroprotection showed increased odds of complicated MRI with aggressive gastrografin enema or surgical treatment compared to nonexposed infants.

Since the observation by Nelson and Grether [4] that antenatal $\mathrm{MgSO}_{4}$ might have fetal neuroprotective effects, subsequent large-scale multicenter RCTs revealed that antenatal $\mathrm{MgSO}_{4}$ use reduced the incidence of cerebral palsy and gross motor dysfunction in preterm infants [5-12]. However, these randomized clinical trials did not include a sufficient number of EPIs born with a GA of 22-25 weeks; therefore, the benefit and the risk of antenatal use of $\mathrm{MgSO}_{4}$ for neuroprotection were not rigorously investigated in these tiny infants. The lowest GA among the infants enrolled in the Australasian Collaborative Trial of Magnesium Sulphate $\left(\mathrm{ACTOMgSO}_{4}\right)$ trial was 25 weeks 5 days; moreover, only $18 \%$ of infants enrolled in the MAGnesium sulphate for Prevention of Eclampsia (Magpie) trial had a GA of $<34$ weeks, and the median GAs of the infants enrolled in the PREterm brain protection by MAGnesium sulphate (PREMAG) and Beneficial Effects of Antenatal Magnesium Sulfate (BEAM) trials were 30 and 28 weeks, respectively [5-8]. Furthermore, Rattray et al. [14] suggested an association between antenatal $\mathrm{MgSO}_{4}$ use and SIP exclusively in EPIs with GA $<25$ weeks. Kamyar et al. [15] also showed a link between antenatal $\mathrm{MgSO}_{4}$ use and NEC in infants with $\mathrm{GA}<26$ weeks. In contrast, in our previous study of premature infants with GAs of 24-31 weeks, exposure to antenatal $\mathrm{MgSO}_{4}$ did not increase the risk of NEC or SIP [26]. This result is in line with those of several recent reports that observed no difference in the odds of NEC or SIP between $\mathrm{MgSO}_{4}$-exposed and -unexposed infants $[27,28]$. In the present study, we also investigated the relationship between antenatal $\mathrm{MgSO}_{4}$ use and intestinal complications including NEC and SIP in younger infants with GAs of 22-25 weeks and observed no significant association. However, we did observe a significant increase in MRI incidence in infants exposed to antenatal $\mathrm{MgSO}_{4}$ compared to that in nonexposed infants.

The association between antenatal $\mathrm{MgSO}_{4}$ use and neonatal meconium problems has long been explored. In the 1970s, Cooney et al. [29] and Sokal et al. [30], respectively, showed that maternal and neonatal hypermagnesemia could result in the development of meconium plug syndrome. As $\mathrm{MgSO}_{4}$ administered to the mother rapidly passes through the placenta, the serum level in the fetus rose immediately. Because $\mathrm{MgSO}_{4}$ is a competitive antagonist of calcium ions, a high $\mathrm{MgSO}_{4}$ level can reduce intestinal contractility, leading to intestinal atony and fecal impaction [20, 31-33]. Simultaneously, $\mathrm{MgSO}_{4}$ administration can compromise mesenteric blood flow and increase cerebral blood flow $[34,35]$. Furthermore, the mineral composition of meconium in preterm infants was found to differ from that in term infants. The meconium in preterm infants had higher concentrations of calcium, copper, iron, and phosphorus than those in term infants [36], leading to underdeveloped intestinal struc- 
tures and functions prone to delayed meconium evacuation after birth in preterm infants. In preterm infants, the first day of meconium passage was delayed compared to that in term infants inversely proportional to the GA [37]. Despite the biologic plausibility and clinical observation that extremely premature babies are prone to MRI $[18,29$, 30, 38], few studies have extensively investigated the risk of MRI in antenatal $\mathrm{MgSO}_{4}$-exposed EPIs.

It is well known that surgical intervention and general anesthesia increase the incidence of neurodevelopmental impairment in preterm infants. Previous studies using national registry data showed that surgery during NICU hospitalization in preterm infants was an independent risk factor for various neurodevelopmental impairments at the age of 2 years or later $[39,40]$. Therefore, the question of whether surgery in this early and vulnerable period of life might offset the beneficial fetal neuroprotective effect should be answered. Although there was no difference observed in the neurodevelopmental outcomes between the periods in our study, randomized trials with predefined primary endpoints and appropriately calculated sample sizes are needed to confirm the effect of fetal neuroprotection in EPIs. Infants with GA $<25$ weeks should be specifically investigated in future RCTs with sufficient power to confirm the causality between antenatal $\mathrm{MgSO}_{4}$ use and postnatal surgical MRI and to reassess the fetal neuroprotective effects of antenatal $\mathrm{MgSO}_{4}$.

It is challenging to differentiate MRI from NEC in EPIs, and stringent diagnosis is a prerequisite for further analysis. In this study, NEC was diagnosed in cases showing definite radiographic evidence of pneumatosis and ascites. The characteristic abdominal and systemic findings of NEC, including abdominal wall bruising, hypotension, bradycardia, coagulopathy, thrombocytopenia, and neutropenia, helped us distinguish NEC from MRI. In addition, all surgical NEC cases showed operative findings of necrotic bowel and postoperative pathologic findings of ischemic necrosis. In contrast, all surgical MRI cases showed jejunal or ileal obstruction by meconium, which was manually extracted, and normal intestinal histology without ischemic necrosis or hemorrhagic infarction.

The limitations of this study include the retrospective nature of the study design and the single-center study design with a relatively small number of patients. $\mathrm{MgSO}_{4}$ usage could not be controlled completely during the study period because of a substantial number of mothers transferred from other hospitals and because antenatal $\mathrm{MgSO}_{4}$ treatment has multiple obstetric indications besides fetal neuroprotection (Table 1). We defined MRI arbitrarily in the present study due to the absence of a commonly ac- cepted definition. Enema procedures with gastrografin are known to be effective in meconium evacuation in preterm infants with delayed meconium passage, thus avoiding the use of surgical resection with enterostomy [41, 42]. However, because these procedures are not a universal practice and the procedure protocol varies worldwide, generalizing our results on the incidence of MRI needs to be done with caution. In addition, the neonatal in-hospital mortality in period 3 was higher than those in periods 1 and 2. While there was no difference in the baseline characteristics, including the gestational age, birth weight, and Apgar score, the cesarean section rate was the lowest in period 3. It is well known that the mode of delivery does not affect the mortality or morbidity rate in preterm infants. However, recent prospective cohort studies and systematic reviews have shown the protective effect of cesarean section on neonatal mortality in EPIs at the threshold of viability [43-45]. Because our study population had an extremely low gestational age ( $\leq 25$ weeks), we speculated that the highest mortality rate in period 3 might be partly attributed to the lowest cesarean section rate, along with the highest histologic chorioamnionitis rate therein. Further analysis adjusting for the cesarean section and chorioamnionitis rates showed no difference in the in-hospital mortality rate between the 3 periods. A recent systematic review showed no association between antenatal $\mathrm{MgSO}_{4}$ treatment and neonatal mortality [46]. Thus, these antepartum and intrapartum factors might have contributed to the difference in the mortality rates between the study periods regardless of antenatal $\mathrm{MgSO}_{4}$ usage. These limitations notwithstanding, the strength of the present study is that the impact of the adoption of antenatal $\mathrm{MgSO}_{4}$ for fetal neuroprotection was clearly demonstrated through changes in MRI-related surgery in friable EPIs before and after the adoption period.

\section{Conclusions}

Our data showed that antenatal $\mathrm{MgSO}_{4}$ use might increase the risk of MRI in EPIs, eventually requiring surgical intervention in a substantial number of cases. No previous studies have rigorously addressed the association of antenatal $\mathrm{MgSO}_{4}$ use and MRI in these extremely tiny babies. Because antenatal $\mathrm{MgSO}_{4}$ is widely used for fetal neuroprotection according to the recommendation by the ACOG and other committees [47], future studies to test the safety and benefit of antenatal $\mathrm{MgSO}_{4}$ regarding the risk of undergoing surgery for MRI are urgently needed in EPIs with GAs of 25 weeks or less.
Sung/Ahn/Choi/Oh/Roh/Yang/Chang/ Park 


\section{Statement of Ethics}

The Institutional Review Board (IRB) of the Samsung Medical Center approved the study and waived the requirement for informed consent for the retrospective chart review (IRB No. SMC 2016-09-113).

\section{Conflict of Interest Statement}

The authors have no conflicts of interest to declare.

\section{Funding Sources}

This study was supported by the SMC-SKKU Future Convergence Research Program Grant.

\section{Author Contributions}

Se In Sung, MD, $\mathrm{PhD}$, contributed to research project conception, organization, and execution; statistical analysis execution; and manuscript preparation - writing of the first draft and review and critique. So Yoon Ahn, MD, PhD, contributed to research project execution, statistical analysis design and review and critique, and manuscript preparation - review and critique. Suk-Joo Choi, $\mathrm{MD}, \mathrm{PhD}$, contributed to research project conception and organization and statistical analysis review and critique. Sooyoung $\mathrm{Oh}, \mathrm{MD}, \mathrm{PhD}$, contributed to research project conception and statistical analysis review and critique. Cheong-Rae Roh, MD, $\mathrm{PhD}$, contributed to research project conception and statistical analysis review and critique. Misun Yang, MD, contributed to research project organization and execution and statistical analysis design and execution. Yun Sil Chang, MD, PhD, contributed to research project conception and organization and manuscript preparation - writing of the first draft and review and critique. Won Soon Park, MD, PhD, contributed to research project conception and manuscript preparation - review and critique.

\section{Data Availability Statement}

Data are available from the institutional ethics committee (contact via the corresponding author) for researchers who meet the criteria for access to confidential data.

\section{References}

1 Grimes DA, Nanda K. Magnesium sulfate tocolysis: time to quit. Obstet Gynecol. 2006; 108(4):986-9.

2 Crowther CA, Brown J, McKinlay CJ, Middleton P. Magnesium sulphate for preventing preterm birth in threatened preterm labour. Cochrane Database Syst Rev. 2014;(8) CD001060.

3 Stelzl P, Kehl S, Rath W. Maintenance tocolysis: a reappraisal of clinical evidence. Arch Gynecol Obstet. 2019;300(5):1189-99.

4 Nelson KB, Grether JK. Can magnesium sulfate reduce the risk of cerebral palsy in very low birthweight infants? Pediatrics. 1995 95(2):263-9.

5 Crowther CA, Hiller JE, Doyle LW, Haslam RR; Australasian Collaborative Trial of Magnesium Sulphate Collaborative Group. Effect of magnesium sulfate given for neuroprotection before preterm birth: a randomized controlled trial. JAMA. 2003;290(20):2669-76.

6 Magpie Trial Follow-Up Study Collaborative Group. The magpie trial: a randomised trial comparing magnesium sulphate with placebo for pre-eclampsia. Outcome for women at 2 years. BJOG. 2007;114(3):300-9.

7 Marret S, Marpeau L, Zupan-Simunek V, Eurin D, Leveque C, Hellot MF, et al. Magnesium sulphate given before very-preterm birth to protect infant brain: the randomised controlled PREMAG trial. BJOG. 2007; 114(3):310-8.
8 Rouse DJ, Hirtz DG, Thom E, Varner MW, Spong CY, Mercer BM, et al. A randomized, controlled trial of magnesium sulfate for the prevention of cerebral palsy. N Engl J Med. 2008;359(9):895-905.

9 Conde-Agudelo A, Romero R. Antenatal magnesium sulfate for the prevention of cerebral palsy in preterm infants less than 34 weeks' gestation: a systematic review and metaanalysis. Am J Obstet Gynecol. 2009; 200(6):595-609.

10 Costantine MM, Weiner SJ; Eunice Kennedy Shriver National Institute of Child Health and Human Development Maternal-Fetal Medicine Units Network. Effects of antenatal exposure to magnesium sulfate on neuroprotection and mortality in preterm infants: a metaanalysis. Obstet Gynecol. 2009;114(2 Pt 1): 354-64.

11 Doyle LW, Crowther CA, Middleton P, Marret $\mathrm{S}$. Antenatal magnesium sulfate and neurologic outcome in preterm infants: a systematic review. Obstet Gynecol. 2009;113(6): 1327-33.

12 Doyle LW, Crowther CA, Middleton P, Marret S, Rouse D. Magnesium sulphate for women at risk of preterm birth for neuroprotection of the fetus. Cochrane Database Syst Rev. 2009;(1):CD004661.
13 American College of Obstetricians and Gynecologists Committee on Obstetric Practice, Society for Maternal-Fetal Medicine. Committee opinion no. 455: magnesium sulfate before anticipated preterm birth for neuroprotection. Obstet Gynecol. 2010;115(3): 669-71.

14 Rattray BN, Kraus DM, Drinker LR, Goldberg RN, Tanaka DT, Cotten CM. Antenatal magnesium sulfate and spontaneous intestinal perforation in infants less than 25 weeks gestation. J Perinatol. 2014;34(11):819-22.

15 Kamyar M, Clark EA, Yoder BA, Varner MW, Manuck TA. Antenatal magnesium sulfate, necrotizing enterocolitis, and death among neonates. AJP Rep. 2016;6(1):e148-54.

16 Kim HY, Kim SH, Cho YH, Byun SY, Han YM, Kim AY. Meconium-related ileus in very low birth weight and extremely low birth weight infants: immediate and one-year postoperative outcomes. Ann Surg Treat Res. 2015;89(3):151-7.

17 Okuyama H, Ohfuji S, Hayakawa M, Urushihara N, Yokoi A, Take H, et al. Risk factors for surgical intestinal disorders in VLBW infants: case-control study. Pediatr Int. 2016;58(1): 34-9.

18 Byun J, Han JW, Youn JK, Yang HB, Shin SH Kim EK, et al. Risk factors of meconium-related ileus in very low birth weight infants: patients-control study. Sci Rep. 2020;10(1): 4674. 
19 Krasna IH, Rosenfeld D, Salerno P. Is it necrotizing enterocolitis, microcolon of prematurity, or delayed meconium plug? A dilemma in the tiny premature infant. J Pediatr Surg. 1996;31(6):855-8.

20 Garza-Cox S, Keeney SE, Angel CA, Thompson LL, Swischuk LE. Meconium obstruction in the very low birth weight premature infant. Pediatrics. 2004;114(1):285-90.

21 Berdon WE, Slovis TL, Campbell JB, Baker DH, Haller JO. Neonatal small left colon syndrome: its relationship to aganglionosis and meconium plug syndrome. Radiology. 1977; 125(2):457-62.

22 Raith W, Resch B, Pichler G, Zotter H, Urlesberger B, Mueller W. Delayed meconium passage in small vs. appropriate for gestational age preterm infants: management and shortterm outcome. Iran J Pediatr. 2013;23(1):812.

23 Redline RW, Faye-Petersen O, Heller D, Qureshi F, Savell V, Vogler C, et al. Amniotic infection syndrome: nosology and reproducibility of placental reaction patterns. Pediatr Dev Pathol. 2003;6(5):435-48.

24 Lee JS, Polin RA. Treatment and prevention of necrotizing enterocolitis. Semin Neonatol. 2003;8(6):449-59.

25 Rigo J, Pieltain C, Christmann V, Bonsante F, Moltu SJ, Iacobelli S, et al. Serum magnesium levels in preterm infants are higher than adult levels: a systematic literature review and meta-analysis. Nutrients. 2017;9(10):1125.

26 Hong JY, Hong JY, Choi YS, Kim YM, Sung $\mathrm{JH}$, Choi SJ, et al. Antenatal magnesium sulfate treatment and risk of necrotizing enterocolitis in preterm infants born at less than 32 weeks of gestation. Sci Rep. 2020;10(1):12826.

27 Downey LC, Cotten CM, Hornik CP, Laughon MM, Tolia VN, Clark RH, et al. Association of in utero magnesium exposure and spontaneous intestinal perforations in extremely low birth weight infants. J Perinatol. 2017;37(6): 641-4.

28 Shalabi M, Mohamed A, Lemyre B, Aziz K, Faucher D, Shah PS, et al. Antenatal exposure to magnesium sulfate and spontaneous intes- tinal perforation and necrotizing enterocolitis in extremely preterm neonates. Am J Perinatol. 2017;34(12):1227-33.

29 Cooney DR, Rosevear W, Grosfeld JL. Maternal and postnatal hypermagnesemia and the meconium plug syndrome. J Pediatr Surg. 1976;11(2):167-72.

30 Sokal MM, Koenigsberger MR, Rose JS, Berdon WE, Santulli TV. Neonatal hypermagnesemia and the meconium-plug syndrome. $\mathrm{N}$ Engl J Med. 1972;286(15):823-5.

31 Hutchinson HT, Nichols MM, Kuhn CR, Vasicka A. Effects of magnesium sulfate on uterine contractility, intrauterine fetus, and infant. Am J Obstet Gynecol. 1964;88:747-58.

32 Dimmitt RA, Moss RL. Meconium diseases in infants with very low birth weight. Semin Pediatr Surg. 2000;9(2):79-83.

33 Siddiqui MM, Drewett M, Burge DM. Meconium obstruction of prematurity. Arch Dis Child Fetal Neonatal Ed. 2012;97(2):F147-50.

34 Havranek T, Ashmeade TL, Afanador M, Carver JD. Effects of maternal magnesium sulfate administration on intestinal blood flow velocity in preterm neonates. Neonatology. 2011;100(1):44-9.

35 Garg BD. Antenatal magnesium sulfate is beneficial or harmful in very preterm and extremely preterm neonates: a new insight. J Matern Fetal Neonatal Med. 2019;32(12): 2084-90.

36 Haram-Mourabet S, Harper RG, Wapnir RA. Mineral composition of meconium: effect of prematurity. J Am Coll Nutr. 1998;17(4):35660.

37 Bekkali N, Hamers SL, Schipperus MR, Reitsma JB, Valerio PG, Van Toledo L, et al. Duration of meconium passage in preterm and term infants. Arch Dis Child Fetal Neonatal Ed. 2008;93(5):F376-9.

38 Shim SY, Kim HS, Kim DH, Kim EK, Son DW, Kim BI, et al. Induction of early meconium evacuation promotes feeding tolerance in very low birth weight infants. Neonatology. 2007;92(1):67-72.

39 Morriss FH Jr, Saha S, Bell EF, Colaizy TT, Stoll BJ, Hintz SR, et al. Surgery and neurode- velopmental outcome of very low-birthweight infants. JAMA Pediatr. 2014;168(8): 746-54.

40 Sung SI, Lee NH, Kim HH, Kim HS, Han YS, Yang M, et al. The impact of surgical intervention on neurodevelopmental outcomes in very low birth weight infants: a nationwide cohort study in Korea. J Korean Med Sci. 2019;34(43):e271.

41 Emil S, Nguyen T, Sills J, Padilla G. Meconium obstruction in extremely low-birthweight neonates: guidelines for diagnosis and management. J Pediatr Surg. 2004;39(5):7317.

42 Karimi A, Gorter RR, Sleeboom C, Kneepkens $\mathrm{CM}$, Heij HA. Issues in the management of simple and complex meconium ileus. Pediatr Surg Int. 2011;27(9):963-8.

43 Hakansson S, Farooqi A, Holmgren PA, Serenius F, Hogberg U. Proactive management promotes outcome in extremely preterm infants: a population-based comparison of two perinatal management strategies. Pediatrics. 2004;114(1):58-64

44 Kallen K, Serenius F, Westgren M, Marsal K, Group E. Impact of obstetric factors on outcome of extremely preterm births in Sweden: prospective population-based observational study (EXPRESS). Acta Obstet Gynecol Scand. 2015;94(11):1203-14.

45 Jarde A, Feng YY, Viaje KA, Shah PS, McDonald SD. Vaginal birth vs caesarean section for extremely preterm vertex infants: a systematic review and meta-analyses. Arch Gynecol Obstet. 2020;301(2):447-58.

46 Shepherd E, Salam RA, Manhas D, Synnes A, Middleton P, Makrides M, et al. Antenatal magnesium sulphate and adverse neonatal outcomes: a systematic review and meta-analysis. PLoS Med. 2019; 16(12):e1002988.

47 De Silva DA, Synnes AR, von Dadelszen P, Lee T, Bone JN, Mag-Cp CPN, et al. MAGnesium sulphate for fetal neuroprotection to prevent Cerebral Palsy (MAG-CP)-implementation of a national guideline in Canada. Implement Sci. 2018;13(1):8. 